\title{
Synthesis and Characterization of Zinc $\beta$-Diketonate Complex Extended to the Macromolecular Polymers
}

\author{
MOHAMMED A. AL-ANBER \\ Department of Environmental Health, Faculty of Public Health \\ and Health Informatics, Hail University, Hail, Saudi Arabia \\ E-mail: (m.alanber@uoh.edu.sa
}

http://dx.doi.org/10.13005/ojc/290420

(Received: September 25, 2013; Accepted: November 30, 2013)

\begin{abstract}
A mononuclear complex of $\left[\mathrm{Zn}(\mathrm{tta})_{2}\left(\mathrm{H}_{2} \mathrm{O}\right)_{2}\right]-(3)-(\mathrm{tta}=$ deprotonated of 1 -thenoyl-4,4,4trifluoroacetone-(1)-has been prepared by the reaction of 1-thenoyl-4,4,4-trifluoroacetone ( $\mathrm{H}$-tta: 1) with $\mathrm{Zn}(\mathrm{OAc})_{2} \cdot 4 \mathrm{H}_{2} \mathrm{O}\left(\mathrm{OAC}=\mathrm{O}_{2} \mathrm{CMe}\right)$ in a $2: 1$ molar ratio complex 3 can be extended to form a coordination polymers of general formula $\left[\mathrm{Zn}(\mathrm{tta})_{2}(\mathrm{X})\right]_{n}\left(\mathrm{X}=4,4^{\prime}\right.$-bipy (4), pz (5) by the reaction of zinc atom in 3 with $\sigma$-donor ligand such as 4,4-bipyridine (4,4'-bipy) and pyrazin (pz). The reaction completion was controlled via FTIR and elemental analysis.
\end{abstract}

Key words: Zinc, 4,4'-Bipyridine, Pyrazine, Polymers, 1-thenoyl-4,4,4-trifluoroacetone.

\section{INTRODUCTION}

Macromolecular coordination polymers including $\beta$-diketonate fragments have attracted widespread attention because of their potential applications as a high quality advanced materials ${ }^{1}$. The design and synthesis of such macromolecular coordination polymer chains can be constructed by binding of metal atom with $\sigma$-donor rod-like bridging ligands such as 4,4'-bipyridine and pyrazine ${ }^{2-4}$. It has been widely observed that such polymeric materials can be influenced by the choice of the metal ion and the bridging ligand species $^{5}$.

A number of supramolecular framework structures including $\beta$-diketonates, such as 1 -(2furyl)-4,4,4-trifluoro-1,3-butanedione (Htfb), 1,1,1trifluoro-2,4-pentanedione $(H-t p)$, and 1-phenyl- 4,4,4-trifluoro-1,3-butanedione (Htpb), with different metal centers, such as $\mathrm{Cu}(\mathrm{II}), \mathrm{Mn}(\mathrm{II}), \mathrm{Ni}(\mathrm{II}), \mathrm{Zn}(\mathrm{II})$ metal ions have been reported ${ }^{6-12}$. Recently, a similar supermolecules structures such as $\left[\mathrm{UO}_{2}(\mathrm{tfb})_{2}\right.$ ] . $\mathrm{OHCH}_{3}$ (tfb = 1-(2-furyl)-4,4,4-trifluoro-1,3butanedione $)^{13},\left[\mathrm{Co}(\mathrm{tta})_{2}\left(\mathrm{OHCH}_{3}\right)_{2}\right]_{n}{ }^{14},\left[\mathrm{Cu}(\mathrm{tta})_{2}\right]$ $n$ (tta $=1$-thenoyl-4,4,4-trifluoroacetone $)^{15}$ have been reported. The moving from the simple complex structure to the metal-organic coordination polymeric chains also have been reported ${ }^{16}$. Mostly, these polymeric chains were formed by reacting of simple cobalt salts with 4,4'-bipyridine (4,4'-bipy) or pyrazine $(\mathrm{pz})^{17-20}$. In this respect, three isomorphus 1D-coordination polymers of [Co(OAc) $)_{2}(4,4$ 'bipy) $]_{n}\left(\mathrm{OAC}=\mathrm{CH}_{3} \mathrm{COO}\right),\left[\mathrm{Co}\left(\mathrm{H}_{2} \mathrm{O}\right)_{3}\left(4,4^{\prime}\right.\right.$-bipy $)$ $\left.\mathrm{SO}_{4}\right] \cdot 2 \mathrm{H}_{2} \mathrm{O}$ and $\left[\mathrm{Co}\left(\mathrm{H}_{2} \mathrm{O}\right)_{3}\left(4,4^{\prime}-\right.\right.$ bipy $\left.) \mathrm{Cl}_{2}\right] \cdot 2 \mathrm{H}_{2} \mathrm{O}$ were synthesized and structurally characterized ${ }^{17}$. The solid-state structures for these polymers show one 
dimensional Co-bipy-Co chains. The polymeric chains of $\left[\mathrm{Co}\left(\mathrm{H}_{2} \mathrm{O}\right)_{3}\left(4,4^{\prime}\right.\right.$-bipy $\left.) \mathrm{SO}_{4}\right] \cdot 2 \mathrm{H}_{2} \mathrm{O}$ are self-assembly stacked through hydrogen bonds producing a 2D-supramolecular network. Similarly, the polymeric structure of $\left[\mathrm{Co}(\mathrm{OAc})_{2}\left(4,4^{\prime} \text {-bipy }\right)\right]_{n}$ contains linear double Co-bipy-Co chains bridged by $\mathrm{CH}_{3} \mathrm{COO}$ groups. From another hand, the synthesis, structure, and reactivity of $\left[\mathrm{Co}(\mathrm{acac})\left(4,4^{\prime}-\text {-bipy }\right)\right]_{n}{ }^{18}$ and $[\mathrm{Co}(\mathrm{acac})(\mathrm{pz})]_{n}$ (acac $=$ acetylacetone, $\mathrm{pz}=$ pyrazine $)^{16}$ polymeric chains were described. The Co atoms in these chains are coordinated in an elongated octahedral geometry with non coplanar of pyridine rings. Between these chains a weak van der Waals interactions were present. Therefore, they may be regarded as essentially $1 \mathrm{D}$-chain structure not as 2D-network. In addition, another isomorphous structure to $\left[\mathrm{Co}(\mathrm{acac})\left(4,4^{\prime} \text {-bipy }\right)\right]_{n}^{18}$ were reported using different metal atom such as [Cu(acac) $(4,4$ 'bipy) $]_{n}{ }^{21}$. Recently, the reaction of $\left[\mathrm{Co}(\mathrm{tta})_{2}\left(\mathrm{H}_{2} \mathrm{O}\right)_{2}\right]$ ${ }^{22}$ with one equivalents of 4,4'-bipyridine (4,4'-bipy) produces 1D-coordination polymer [Co(tta)(4,4'-bipy)] ${ }_{n}^{14}$, whereby the supramolecularity, structurally and thermally of $\left[\mathrm{Co}(\mathrm{tta})\left(4,4^{\prime}-\text { bipy }\right)\right]_{n}$ are characterized. These 1D-polymeric chains are stacked through the presence of $S \ldots S$ intermolecular interactions between thiophene rings of individual chains.

In this context, we have synthesized a $\left[\mathrm{Zn}(\mathrm{tta})_{2}\left(\mathrm{H}_{2} \mathrm{O}\right)_{2}\right](3)$ complex and three kind of coordination polymers of $\left[\mathrm{Zn}(\mathrm{tta})_{2}(\mathrm{X})\right]_{n}\left(\mathrm{X}=4,4^{\prime}\right.$-bipy (4), pz (5), 1,4-dip (6); tta = deprotonated of 1-thenoyl4,4,4-trifluoroacetone) by the reaction of zinc atom in 3 with s-donor ligand such as 4,4-bipyridine (4,4'bipy), pyrazin (pz), and 1,4-diisocyanobenzene (1,4dip).

\section{EXPERIMENTAL}

\section{General remarks}

All chemicals were purchased from commercial providers (Fluka Company) and were used as received.

\section{Physical measurements}

Infrared spectra were recorded using a Perkin-Elmer FTIR 1000 spectrometer. Melting points were determined using analytically pure samples with a Gallenkamp MFB 595 010M melting point apparatus. Microanalyses were performed using a Thermo FLASHEA 1112 Series instrument.
Thermogravimetric studies were carried out with the Perkin Elmer System Pyris TGA 6 with a constant heating rate of $8 \mathrm{~K} \mathrm{~min}^{-1}$ under $\mathrm{N}_{2}\left(20.0 \mathrm{dm}^{3} \mathrm{~h}^{-1}\right)$.

\section{Synthesis of $\left[\mathrm{Zn}(\mathrm{tta})_{2}\left(\mathrm{H}_{2} \mathrm{O}\right)_{2}\right](3)$}

Complex 3 is accessible by the reaction of $\mathrm{Zn}(\mathrm{OAc})_{2} \cdot 4 \mathrm{H}_{2} \mathrm{O}$ (98.8 mg, $\left.0.45 \mathrm{mmol}\right)$, dissolved in $50 \mathrm{ml}$ hot ethanol and tta $(199.9 \mathrm{mg}, 0.9 \mathrm{mmol})$. The reaction was stirred in ethanol for 5 hours. Enough distal water was added to precipitate the product and then washed several times with petroleum ether. The product dried under vacuum several days. A white (Zn) solid was obtained in the yield of $88 \%$. Mp: 177 $-180^{\circ} \mathrm{C}$. IR (KBr), $\mathrm{cm}^{-1}: 3426$ (b, vs) (O-H); 3104 (m) (C-H); 1601 (vs) (CO); 1578 (vs), 1540 (vs), 1508 (s) (C-C); 1458 (s), 1410 (vs), 1352 (s), 1303 (vs), 1255 (s), 1233 (s) (thienyl ring); 1190 (vs) $\left(v_{\mathrm{C}-\mathrm{F}}\right) ; 846$ (s), 861 (s), 933 (s) (C-H out-plane thienyl); 790 (s), 723 (s) $\left(v_{\text {C-CF } 3}\right)$. Anal. Calc. for $\mathrm{C}_{16} \mathrm{H}_{8} \mathrm{~F}_{6} \mathrm{O}_{4} \mathrm{~S}_{2} \mathrm{Zn}(507.5612$ $\mathrm{g} / \mathrm{mol}$ ): C, $37.85 \%$; H, $1.59 \%$. Found: C, $37.30 \%$; $\mathrm{H}, 1.90 \%$.

\section{Synthesis of $\left[\mathrm{Zn}(\mathrm{tta})_{2}\left(4,4^{\prime}-\mathrm{bipy}\right)\right]_{\mathrm{n}}(4)$}

Polymer $\mathbf{4}$ is accessible by the reaction of $\mathrm{Zn}(\mathrm{OAc})_{2} \cdot 2 \mathrm{H}_{2} \mathrm{O}(98.8 \mathrm{mg}, 0.45 \mathrm{mmol})$, dissolved in 50 $\mathrm{ml}$ hot ethanol and tta $(199.9 \mathrm{mg}, 0.9 \mathrm{mmol})$. After 5 hours of stirring at room temperature, $(70.3 \mathrm{mg}, 0.45$ $\mathrm{mmol}$ ) of $4,4^{\prime}$-bipyridine was added as one portion. A white precipitate was appeared after 20 minutes, and resulting solution was stirred continuously for another 5 hours at room temperature. The precipitate was filtered off, washed with chloroform, ethanol, water, and then dried under vacuum for several days to produces a white solids. Yield of $92 \%$. Mp: $318^{\circ} \mathrm{C}$. IR (KBr), $\mathrm{cm}^{-1}: 1600$ (vs) (CO); 1580 (vs) (C-C); 1539 (s), 1507 (s), 1469 (s), 1413 (s), 1352 (s) (thienyl ring); 1299 (vs), 1255 (s), (C-C and C-R); 1231 (s), 1188 (vs) $\left(\mathrm{n}_{\mathrm{C}-\mathrm{f}}\right) ; 1150$ (s), 1131 (vs) (C-H in-plane thienyl). Anal. Calc. for $\mathrm{C}_{26} \mathrm{H}_{16} \mathrm{~F}_{6} \mathrm{~N}_{2} \mathrm{O}_{4} \mathrm{~S}_{2} \mathrm{Zn}(663.41 \mathrm{~g} / \mathrm{mol})$ : C, $47.10 \% ; \mathrm{H}, 2.41 \%$; N, $4.23 \%$. Found: C, $46.93 \%$; $\mathrm{H}, 2.49 \% ; \mathrm{N}, 4.22 \%$.

\section{Synthesis of $\left[\mathrm{Zn}(\mathrm{tta})_{2}(\mathrm{pz})\right]_{\mathrm{n}}(5)$}

Polymer $\mathbf{5}$ is prepared in an analogous manner to polymer 4 . In this respect, $\mathrm{Zn}(\mathrm{OAc})_{2} \cdot 2 \mathrm{H}_{2} \mathrm{O}$ (98.8 mg, $0.45 \mathrm{mmol})$, tta (199.9 mg, $0.9 \mathrm{mmol}$ ) and pyrazine ( $36.04 \mathrm{mg}, 0.45 \mathrm{mmol}$ ) were used producing a light white solids in a yield of $90 \%$. Mp: $270{ }^{\circ} \mathrm{C}$. IR (KBr), cm ${ }^{-1}: 1601.35$ (vs), 1579.61 (s, shoulder) $\left(\mathrm{CO}, v_{\mathrm{as}}\right) ; 1539.93(\mathrm{~s})\left(\mathrm{CO}, \mathrm{v}_{\mathrm{as}}\right) ; 1457.61$ (s) (CO, $\left.\mathrm{n}_{\mathrm{s}}\right)$; 
1409.61 (s) (CO, $\left.\mathrm{n}_{\mathrm{s}}\right) ; 1303.78$ (s) ( $\left.\mathrm{v}_{\mathrm{C}-\mathrm{F}}\right)$. Anal. Calc. for $\mathrm{C}_{20} \mathrm{H}_{12} \mathrm{~F}_{6} \mathrm{~N}_{2} \mathrm{O}_{4} \mathrm{~S}_{2} \mathrm{Zn}(587.94 \mathrm{~g} / \mathrm{mol}): \mathrm{C}, 40.90 \% ; \mathrm{H}$, $2.04 \%$; N, $4.76 \%$. Found: C, $41.44 \%$;, $1.99 \%$; $\mathrm{N}, 4.29 \%$.

\section{RESULT AND DISCUSSION}

\section{Synthesis and characterization}

The reaction of 1-thenoyl-4,4,4-trifluoroacetone ( $H$-tta: 1) with $\mathrm{Zn}(\mathrm{OAc})_{2} \cdot 4 \mathrm{H}_{2} \mathrm{O}(\mathrm{OAc}=$ $\left.\mathrm{O}_{2} \mathrm{CMe}\right)$ in a 2:1 molar ratio gave $\left[\mathrm{Zn}(\mathrm{tta})_{2}\left(\mathrm{H}_{2} \mathrm{O}\right)_{2}\right](3$ : $\mathrm{tta}=$ deprotonated of 1) complex in ethanol, which was isolated white solid after precipitation upon treatment with aqua (Scheme 1). The produced complex is soluble with most common organic solvents including tetrahydrofuran, acetonitrile, and ethanol. However, in water and non-polar solvents 3 is not soluble. This complex is stable in both solution and solid state under the normal conditions. This stability may due to the presence of intermolecular forces between the mononuclear complex spheres of 3 , as shown in the reported structures ${ }^{14}$. The gentle heating of the title complex solid, in an oven up to $180 \stackrel{\circ}{ } \mathrm{C}$, change the solubility to be non soluble in various organic solvents. The poor solubility indicates for turning into the di- or polynuclear ones by oligomerization through the bridging oxygen atoms of diketonate unit as known and observed of such systems ${ }^{22}$.

Complex 3 can be extended to infinite coordination polymers of $\left[\mathrm{Zn}(\mathrm{tta})_{2}(\mathrm{X})\right]_{n}\left(\mathrm{X}=4,4^{\prime}\right.$-bipy (4), pz (5)) by the reaction of zinc atom in 3 with 4,4bipyridine (4,4'-bipy) and pyrazin (pz) in warm ethanol in a 1:1 molar ratio (Scheme 1). These polymers can also be prepared directly by stoichiometric reacting of $\mathrm{Zn}(\mathrm{OAc})_{2} \cdot 4 \mathrm{H}_{2} \mathrm{O}\left(\mathrm{OAc}=\mathrm{O}_{2} \mathrm{CMe}\right)$ with 1 and $\sigma$-donor ligand in 1:2:1 molar ratio, respectively for 6 hours of reaction stirring (Scheme 1). The aqua ligands in 3 are eliminated by a strong $\sigma$-donor bridging ligand forming 4-5, wherein the complex and polymeric structures were proposed according the reported of similar materials ${ }^{13,14,16-21}$. The solutions and solids of polymers are stable in air. After appropriate workup, polymers $\mathbf{4}$ - $\mathbf{5}$ could be isolated as white solid. They are none dissolving in most common organic solvents including tetrahydrofuran, acetonitrile, and ethanol. However, in water and non-polar solvents also are not soluble.

The elemental analyses of $\mathbf{3} \mathbf{- 5}$ agree with their formula as shown in Experimental section. The chemical nature is characterized by Ft-IR

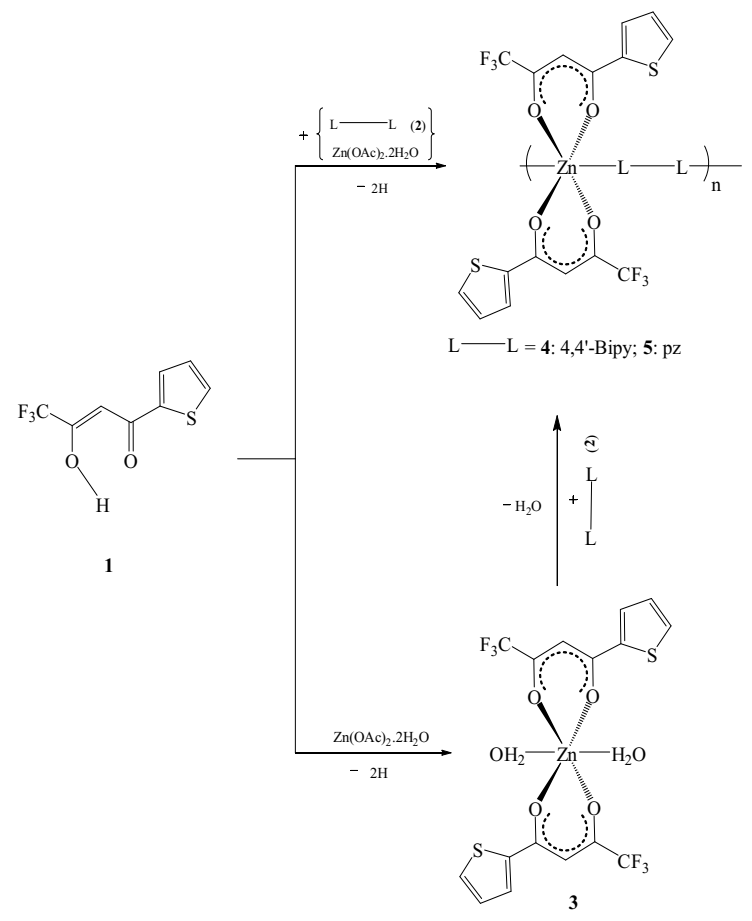

Scheme 1: Synthesis 3-5 
The reaction progress of $\mathbf{1}$ with 2 could additionally be controlled by IR spectroscopy, since the characteristic absorptions of the free non-coordinated $\beta$-diketone $\mathrm{H}$-tta disappeared during the course of the reaction and new bands characteristic for metal $\beta$-diketonato species were observed (Experimental). IR spectrum of $\mathbf{3}$ shows prominent absorptions at $3426 \mathrm{~cm}^{-1}$ (ascertains the presence of coordinated aqua ligands ${ }^{23}$ ) and 1601 - $1410 \mathrm{~cm}^{-1}$ (typical for metal $\beta$-diketonate complexes $^{24-25}$. IR spectroscopy can also be used to monitor the elimination of the aqua ligands in $\mathbf{3}$ by thermal treatment because the very characteristic vibrations of the aqua ligands continuously disappear with progress of the reaction ${ }^{14,24}$. The peaks at $1601,1578,1540$, and 1508 are assigned to the keto-enol tautomerism chelating ring of $v_{\mathrm{C}=\mathrm{O}}$ and $v_{\mathrm{C}=\mathrm{C}}$ stretching vibrations ${ }^{18}$. The observed downfield shift, going from free ligand $\left(1: v_{\mathrm{C}=\mathrm{O}}=1652\right.$ and $v_{\mathrm{C}=\mathrm{C}}=1580 \mathrm{~cm}^{-1}$ ) to the corresponding vibrations in 3 indicates for the complexation, which found in consistent with the reported one ${ }^{19}$. The presence of these bands and their shifts $\left(\Delta v_{C=0}\right)$ should be regarded as a characteristic stretching vibrations of keto-enol tautomerism chelating ring of tta ligands with $\mathrm{Zn}(\mathrm{II})$ centre as a whole, as in case of benzene 20. The appearance of a vibration at $3104 \mathrm{~cm}^{-1}$ indicates the formation of hydrogen bonds in $3^{26}$, this can be considered as evidence for the formation of supramolecular complexes in solid state. The stretching vibration of $v_{\mathrm{C}-\mathrm{F}}$ for the coordinated tta, is found at $723 \mathrm{~cm}^{-1}(3)$. This vibration is shifted to a somewhat lower frequency (for comparison $\mathrm{H}$-tta (1): $\left.732,746 \mathrm{~cm}^{-1}\right)$. The stretching vibration of the $\mathrm{C}-\mathrm{H}$ out-of-plane of thienyl ring at $803 \mathrm{~cm}^{-1}$ in 1 is shifted to the lower frequency upon complexation in 3 , which is observed at $790 \mathrm{~cm}^{-1}$.

The reaction progress of $\mathbf{3}$ with s-donor bridging ligand can be controlled by IR spectroscopy, since the characteristic absorptions of the coordinated aqua ligands in $3{ }^{14}$ disappeared during the course of the reaction. This indicates the successful substituting the terminal aqua ligands in 3 by $4,4^{\prime}$-bipy and $p z$ ligands forming $4-5$. As result of changing the aqua ligands in 3 with strong $\pi$-donor bridging ligand such as 4',4-bipyridine ligand, the stretching vibration of $\mathrm{C}_{-}-\mathrm{CF}_{3}$ shifted to the lower frequency (712 $\left.\mathrm{cm}^{-1}\right)$ compared to $3\left(723 \mathrm{~cm}^{-1}\right)$. Furthermore, the stretching vibrations of $\mathrm{C}-\mathrm{H}$ of thenoyl ring shifted to the lower frequencies $\left(3105 \mathrm{~cm}^{-1}\right)$ compared to $3\left(3102 \mathrm{~cm}^{-1}\right)$. This is ascribed to an increase in the $\pi$-donating and in the back-donating form $\mathrm{Zn}(\mathrm{II}) \rightarrow$ tta. IR spectrum shows the prominent absorptions in the range of $1600-1413 \mathrm{~cm}^{-1}$ (typical for metal $\beta$-diketonate complexes ${ }^{12,14,27-29}$ ).

Due to the poor solubility of $\mathbf{4}$ - $\mathbf{5}$ polymers the UV-Vis spectroscopy cannot be measured.

\section{CONCLUSION}

The mononuclear complex 3 has been successfully prepared and characterized by FTIR. The produced complex is extended to infinite metal-organic coordination polymer of $\left[\mathrm{Zn}(\mathrm{tta})_{2}(\mathrm{X})\right]$ ${ }_{n}(X=4,4$ '-bipy (4), pz (5)). Complex 3 is formed in enol-tta system. The formation of hydrogen bonds can be considered as evidence for the formation of supramolecular complex of 3 in solid state.

\section{REFERENCES}

1. (a) Bourne S. A., Lu J. J., Mondal A., Moulton B. and Zaworotko M. J., Angew. Chem., Int. Ed. Engl., 40: 2011 (2001)

(b) Holiday B. J. and Mirkin C. A., Angew. Chem., Int. Ed. Engl., 40: 2022 (2001).

2. M-C. Dul, E. Pardo, R. Lescouëzec, Y. Journaux, J. Ferrando-Soria, R. Ruiz-García, J. Cano, M. Julve, F. Lloret and D. Cangussu, Coord. Chem. Rev., 254: 2281(2010).

3. J.W. Steed and J. L. Atwood, Supramolecular Chemistry, (Wiley: USA) (2005).

4. G. R. Desiraju, Angew. Chem., Int. Ed. Engl.
34: 2311 (1995).

5. T. Kuroda-Sowa, T. Horrino, M. Yamamoto, Y. Ohno, M. Maekawa and M. Munakata, Inorg. Chem., 36:6382 (1997).

6. H.M. Daoud, M.Sc Thesis, supervised by Dr. Mohammed Ahmed Al-Anber, Mutah University (2009).

7. M.A. Al-Anber, Mahdi Lataifeh, Haneen Dawoud, J. Macromolecular Sci.: Part B, Physics, 52: 344 (2013).

8. D. Ma, Y. Wu and X. Zuo, Material letters, 59:3678 (2005). 
9. H. Gallardo, G. Conte, P. Tuzimoto, A. Bortoluzzi, R. A. Peralta and A. Neves, Inorg. Chem. Commun., 11: 1292 (2008).

10. P. A. Vigato, V. Peruzzo and S. Tamburini, Coord. Chem.Rev., 253: 1099 (2009).

11. H. O. Omoregie and J.A.O. Woods. Archives App. Sci. Res., 2(4): 7-16 (2010).

12. M. A. Al-Anber, Int. J. Chem. Sci. Techno. 3(1): 40 (2013).

13. M. Al-Anber, H. Daoud, T. Ruffer and H. Lang, J. Mol. Struct., 997: 1 (2011).

14. M. Al-Anber, P. Ecorchard, T. Rüffer and H. Lang, Main group Chem., 11: 205 (2012).

15. M. A. Al-Anber, H. M. Daoud, T. Rüffer, H. Lang, Arabian J. Chem. In press (2012) DOI: 10.1016/j.arabjc.2012.04.048

16. A.W. Maverick, F. R. Fronczek, E. F. Maverick, D. R. Billodeaux, Z. T. Cygan and R. A. Isovitsch, Inorg. Chem., 41: 6488 (2002).

17. J. Lu, C. Yu, T. Niu, T. Paliwala, G. Crisci, F. Somosa and A. J. Jacobson, Inorg. Chem., 37: 4637 (1998).

18. B-Q.Ma, S. Gao, T.Yi and G-X.Xu, Polyhedron, 20: 1255 (2001).

19. C. Chen, D. Xu, Y. Xu, C. Cheng, Acta Crystallogr., Sect. C, 48: 1231 (1992).

20. M.J. Plater, M.R. St. Foreman and A.M.Z. Slawin, Inorg. Chim. Acta 303: 132 (2000).
21. Y.Z. Xu and S.Shi, Acta Chim. Sini., 44: 336 (1986).

22 a) A. I. Matesanz, I. Cuadrado, C. Pastor and P. Souza, Zeitschrift für anorganische und allgemeine Chemie, 631: 780 (2005).

b) M. Al-Anber, P. Ecorchard, T. Rüffer and H. Lang, 2014, in preparation.

22. A. I. Matesanz, I. Cuadrado, C. Pastor and P. Souza, Zeitschrift für anorganische und allgemeine Chemie, 631: 780 (2005).

23. M.A. Hassaan Aly and M.G. Marei, J. Indian Chem. Soc., 70: 64 (1993).

24. K. Jeyasubramanian, S. Abdul Samath, S. Tambidurai, R. Murugesan and S. K. Ramalingam, Trans. Met. Chem., 20:76 (1995).

25. J. Lu, C. Yu, T. Niu, T. Paliwala, G. Crisci, F. Somosa and A. J. Jacobson, Inorg. Chem., 37: 4637 (1998).

26. M. Indrani, R. Ramasubramanion, S. Kumaresan, S.K. Kang, M. Chen and M. Du, Polyhedron, 27: 3593 (2008).

27. M. A. Al-Anber, Int. J. Chem. Sci. Techno., 3(1): 33 (2013).

28. M. A. Al-anber, Orient. J. Chem., 29(3): 829 (2013)

29. M. A. Al-anber, H. Daoud, Orient. J. Chem., 29(3): 901 (2013). 